DOI: $10.2478 /$ pof-2018-0040

VOLUME 10, ISSUE 3, 2018

ISSN: 2036-5438

\title{
Environmental subsidiarity in the EU: \\ or halfway to green federalism?
}

\author{
by
}

Tiago de Melo Cartaxo*

Perspectives on Federalism, Vol. 10, issue 3, 2018 


\begin{abstract}
Environmental protection and sustainable development are competences that the EU is entitled to integrate into the definition and implementation of its policies. However, shared competences in these areas are still a reality, as a margin of discretion persists for Member States, aimed at maintaining a high level of decentralisation, particularly where issues related to national policies and more (nation) specific sectoral legislation are concerned. This paper intends to analyse the application of the principle of subsidiarity to environmental issues within the EU, to examine the characteristics of a possible path to the future of green federalism in Europe.
\end{abstract}

Key-words

subsidiarity principle, green federalism, decentralisation, environmental law, EU law 


\section{Introduction}

The realities of environmental protection and sustainable development are not new topics of concern at the European level. Nevertheless, in recent years these themes have taken on a new importance, with the urgent need to find local and global solutions to climate change, the erosion of biodiversity, depletion of natural resources and, more generally, to 'global environmental damage' (Sadeleer 2012: 74).

As a matter of fact, the European Union (EU) governance and law-making institutions have had considerable influence on environmental regulation and policy in the territories of Member States, especially since the last decades of the $20^{\text {th }}$ century, when European integration started to be a more consistent reality. Therefore, according to the principles and norms of the Treaties and also the Charter of Fundamental Rights of the European Union, environmental protection and sustainable development are issues which the Union is entitled to integrate into the definition and implementation of its policies and activities.

However, shared competences in the areas of environment are still a reality, as a large margin of discretion should persist for the powers of Member States, aimed at maintaining a high level of decentralisation within the Union regarding these matters, particularly where issues related to national policies and more sectoral legislation are concerned (van Zeben 2014: 419).

Examples of shared competences utilised by the European institutions include: directives on environmental impact assessment of projects and programmes; industrial emissions; the EU emissions trading system (EU ETS); regulations concerning the registration, evaluation, authorisation and restriction of chemicals $(\mathrm{REACH})$; and the protection of species of wild fauna and flora though the regulation of their trade. Moreover, Member States are obliged to implement those directives through national statutory laws, and comply with these regulations (or more infrequently, decisions), which have particular effects depending on the form of the legal instrument (Martella and Francke 2012: 8-13).

This path of building an integrated European acquis and harmonisation of national laws of Member States, specifically in environmental areas, has played an important role in enhancing the awareness of the whole Union (including national governments and their 
citizens) in regard of the principles and main priorities that are intrinsic to the European project.

Nevertheless, principles of subsidiarity and proportionality are understood as establishing that decisions should be made at the most local level possible (i.e. nationally or regionally) and that EU action should be limited to the minimum necessary to achieve the intended objectives. In reality, legal and political problems arise in cases in which the implementation of directives leads to uneven application by national institutions. As a consequence, some directives are revised and reintroduced as regulations, or Member States are subject to the 'EU-Pilot' schemes to resolve compliance problems which, if not resolved, usually result in infringement proceedings (Martella and Francke 2012: 8-13).

However, the truth is that, in some situations, this uneven application may be caused by a simple interpretation of those 'centralised' committees, agencies and organs of the European institutions; in these cases subsidiarity and proportionality play a fundamental role in the relation between the European institutions (and their agencies' unchecked rulemaking powers), national governments and parliaments, which are entitled to approve the legal instruments, and the principles of democracy and participation in Member States.

This paper intends to analyse the different shades of grey that, therefore, may exist between the principle of subsidiarity as foreseen in the Treaties and conceivable characteristics of an environmental variant of federalism within the EU.

\section{Subsidiarity and the environment}

Where the topic of subsidiarity is concerned, it should be emphasised, right from the outset, that this principle was primarily and expressly introduced in the European Treaties through the Single European Act (1986), which added a Title VII to Part Three of the European Economic Community (EEC) Treaty and introduced Article 130r(4). ${ }^{\mathrm{I}}$ At that time, curiously, it was only applicable to environmental issues, but the Treaty of Maastricht (1992) resulted in its extension, to become a more general and overarching principle of both the European Community (EC) Treaty, inserting it in Article 3b, ${ }^{\mathrm{II}}$ and the Treaty on the European Union, through the last paragraph of Article B. ${ }^{\text {II }}$

Following that, in a 1993 report regarding the subsidiarity principle, the European Commission stated that 
(...) the risk of encountering resistance from national administrations which, because of a mutual lack of confidence, are anxious to obtain the most detailed regulations possible. ${ }^{\text {IV }}$

In the same document, the Commission defended that subsidiarity

is first and foremost a political principle, a sort of rule of reason. Its function is not to distribute powers. That is a matter for (...) the authors of the Treaty. The aim of the subsidiarity principle is, rather, to regulate the exercise of powers and to justify their use in a particular case.

Then, with the Treaty of Amsterdam (1997), a Protocol (No 30) on the Application of the Principles of Subsidiarity and Proportionality was adopted, in order to clarify when and in which measure subsidiarity could and should be applied. ${ }^{\mathrm{V}}$

In 2007, the Treaty of Lisbon moved the principle of subsidiarity to Article 5(3) TEU ${ }^{\mathrm{VI}}$ with a new Protocol (No 2) appended, on the Application of the Principles of Subsidiarity and Proportionality, ${ }^{\text {VII }}$ explicitly referring for the first time to regional and local levels in the provision concerning the subsidiarity principle and rendering a new approach of subsidiarity, more inclusive than that of the former treaties (Arribas and Bourdin 2012: 1317).

However, the idea that government should be no more centralised than strictly necessary, for it to achieve the objectives assigned to its powers, had been a reality since the earliest stages of European integration. Indeed, even the original version of the Treaty of Rome, in 1957, assumed this principle (albeit roughly) when shaping the legislative, executive, and judicial powers of and within the Community. Therefore, the TEU demonstrated, from its very beginning (Article 1, second paragraph) ${ }^{\mathrm{VIII}}$ the option of marking 'a new stage in the process of creating an ever closer union among the peoples of Europe, in which decisions are taken as closely as possible to the citizen'.

As a matter of fact, this legal option also reflects aspirations of balancing the path of integration, through the extension of the powers conferred to the Union, and the maintenance of confidence in the Member States and their subnational authorities and citizens, guaranteeing the proximity of government and assuring that integration must not be synonymous with centralisation (Lenaerts 1993: 846-895). 
According to the provisions of Article 5(3) TEU, two conditions must be met for the EU to be able to take measures in which it has non-exclusive competence: (i) if the objectives of the proposed action cannot be sufficiently achieved by the Member States; and (ii) if those objectives can, because of their scale and effects, be better achieved at a higher level by the EU. In addition, following the procedure of the protocol, the Commission 'shall consult widely' and must explain in its proposal why it is necessary that the EU take action in each specific situation. ${ }^{\mathrm{IX}}$ It should also be emphasised that the reasons for concluding that a Union objective can be better achieved at Union level shall be substantiated by qualitative and, wherever possible, quantitative indicators' ${ }^{\mathrm{X}}$

Nevertheless, assessments on whether certain objectives can (or not) be better achieved at the EU level are not absolutely clear and commonly accepted by all EU institutions and Member States. For example, northern European Member States usually have more ambitious environmental agendas and, therefore, would probably enact certain green policies or measures without the spur of the EU. On the other hand, other Member States would probably not take such environmental measures if the EU did not enact commensurate decisions or legislation and, in some cases, acting at EU level can be the only way to ensure that effective environmental policy is enacted throughout the whole territory of the EU (Krämer 2012: 18).

In this sense, environmental legal acts typically fulfil the requirements of the subsidiarity principle (Jans and Vedder 2012: 14), since most environmental problems are by their very nature transboundary, coordinated or harmonising policies and measures are considered to be the most effective option to tackle problems such as pollution or the existence of hazardous substances. Additionally, some environmental protection measures enacted by Member States individually may generate negative effects or externalities on the internal market and competition within the EU. ${ }^{\mathrm{XI}}$ This means that action by the EU represents a way to avoid such possible distortions since all EU actors would be subject to the same requirements, or at least common minimum rules, depending on the form of the legal act (from decisions to regulations and directives). And that is why Sadeleer states that:

The principle of subsidiarity is inherent in the European institutional architecture. In any case, the environmental domain does not escape. It could even be argued that this principle could serve as a testbed for the exercise of a shared competence, whereas the principle of proportionality had the effect of 
regulating the exercise of those powers in the sense of a very harmonised approach which leaves a considerable margin of appreciation to the State entities. (Sadeleer 2012: 89)

Protocol (No 2) on the Application of Subsidiarity and Proportionality Principles consequently gave the opportunity ${ }^{\mathrm{XII}}$ for national parliaments to review a legislative proposal that may be not in accordance with the subsidiarity principle (Barnard and Peers 2014: 112-113). This mechanism in the protocol is predicated on the idea that the application of the subsidiarity principle, on whether the EU can legally adopt a legal act, is more appropriate for ex ante political control rather than for expost judicial control (Langlet and Mahmoudi 2016: 46-48).

It should also be mentioned that, as the protocol clearly demonstrates, subsidiarity is strictly connected to the principle of proportionality, which is set in Article 5(4) TEU. XII According to this principle, there is a myriad of environmental legal acts that only assume the character of framework directives, leaving a relatively wide scope for Member States to adopt concrete and more adaptable measures and policies in order to achieve the objectives of the EU law, ${ }^{\mathrm{XIV}}$ hence balancing the European integration process between a path of both subsidiarity and proportionality.

On this topic it would be noteworthy to emphasise that, from Sadeleer's perspective

...the principle of subsidiarity can be examined from two different angles. The first is part of the division of powers between the Union and the Member States, while the second concerns new modes of regulation, namely co-regulation and self-regulation (Sadeleer 2012: 89).

And, while assessing if the protection of the environment is better ensured by the increased role played by subsidiarity, the author considers that the majority of experts highlight that subsidiarity had contributed to exacerbating a phenomenon of decentralisation and deregulation to the detriment of a centralised and coherent right.

In effect, on this issue, Sadeleer continues his reasoning stating that

This combined phenomenon of decentralization and deregulation seems to contribute more to aggravating ecological crises than to curbing them. After four decades of environmental policy, the record has indeed nothing positive. ... environmental threats will only be eliminated through coherent policies requiring joint efforts to achieve a high level of protection. 
As a matter of fact, federal systems assume as their fundamental concern the need to balancing the regulatory power of the central and local levels. And subsidiarity is one of the most relevant and accurate legal tools for maintaining that balance (van Zeben 2014: 416), especially in what is often called the 'sui generis system of governance' that characterises the EU (Kohler-Koch and Eising 1999).

\section{Green federalism?}

In effect, the path to a federalisation (or at least a para-federalisation) of European environmental law and policy has followed a gradual development throughout the six decades of the integration process. In fact, in the beginning the Treaty of Rome contained no provision providing for environmental regulation; nonetheless, more than 70 environmental directives were adopted between 1973 and 1983 (Vogel et al. 2010: 2).

Following the enactment of the Single European Act in 1987, which, as already explained above, provided a clear legal basis for EC environmental policy and eased the procedures for the approval of environmental directives, EC environmental policy-making tended to accelerate. Originally primarily motivated by the need to prevent divergent national standards from undermining the single market, environmental law and policy became an increasingly important focus for the EC and then the EU. Each successive treaty has strengthened the European commitment to a responsibility for improving environmental quality and promoting sustainable development throughout Europe.

From van Zeben's perspective, the reality of the EU 'falls short of a federal system but achieves a level of integration that goes beyond that of an international organization' and, as a result, it is constructed out of a unique combination of institutional features that are typically only found in international organisations or nation states, but not in one single system (van Zeben 2014: 421).

van Zeben stressed the fact that, at times, the application of principles that developed within a domestic federal setting tend to prove problematic, as their meaning changes together with their institutional setting. The subsidiarity principle appears to be a prime example of such a phenomenon. The virtues ascribed to subsidiarity in the European context are very similar to those ascribed to, for instance, American federalism. From self- 
determination and accountability, to political liberty, or flexibility, preservation of identities, diversity and respect for internal division of component states. These elements are also part of European integration.

Logically, the objectives of diversity and the preservation of identities carry different weight and meaning in a union of sovereign nations when compared to a federal nation state such as the United States (US). At the same time, the relationship between individual citizens and the EU institutions - the role of individuals within the democratic process of the EU, as well as its way of governing - is distinct from that of national citizen and a federal government, as properly considered in the US.

It is, as a matter of fact, relevant to mention that there are substantive differences between the European and American systems; even in the language it is possible to notice the risks of comparison. As an example, when American scholars refer to 'national standards', they mean federal standards as opposed to local or state standards, while at the same time, for European scholars, 'national standards' necessarily refer to standards approved and set by the national Member States, as opposed to either local or European standards (Faure and Johnston 2009: 271). ${ }^{\mathrm{xV}}$

In fact, in the US, the path to a greater centralisation of environmental law and policymaking occurred relatively rapidly compared to the EU. In the mid-1970s (the so-called 'environmental decade'), federal standards were established for virtually all forms of air and water pollution. ${ }^{\mathrm{XVI}}$ Effectively, by the end of the decade, federal regulations already governed the protection of endangered species, drinking water quality, pesticide approval, the disposal of hazardous wastes, surface mining, and forest management, among other policy areas, through the implementation of a new and massive federal pollution control regulatory structure (Gottlieb 1993: 148-157). This process was, in point of fact, strongly supported by pressure from environmental activists, who believed that federal regulation was more likely to be effective than regulation at the state level (Vogel et al. 2010: 1-41).

However, the US system of federal environmental regulation does not completely displace state regulation. Regulators at the federal Environmental Protection Agency (EPA) set minimum, technology-based emission standards; state regulators then generally assume the authority to implement general standards by writing plant-specific permits, and to monitor and enforce compliance with permit terms. Although there are exceptions, for the most part states are free to set state emission standards that are even tougher than federal 
standards. Moreover, in translating national standards into site-specific permits, states are often legally permitted to give more weight to the cost of compliance than are federal regulators. This could be considered as a system of cooperative environmental federalism (Faure and Johnston 2009: 214-217).

On the other hand, in the EU, Member States are sovereign nations, and currently there is still substantial environmental regulatory authority remaining with the Member States. In effect, under the principle of conferral (or attribution), foreseen in Article 5(1) XVII and $(2)^{\mathrm{XVIII}}$ TEU, EU powers extend only as far as expressly confirmed by the treaty. Despite this principle, the power of the 'European bureaucracy' has increased, and led to a shift of environmental regulatory competences to the European institutions. This means that a large amount of environmental legislation in the territories of Member States is European law or influenced by European law, consisting of directives which must be transposed into national law - or even regulations directly applied in the territories of Member States.

Therefore, as European environmental law directives are only indirectly effective, through Member State environmental laws which must be enacted or revised to comply with European standards, some authors would contend that the actual strength of European environmental law depends upon the enforcement of European environmental law by Member States (Krämer 2002: 178-182). Nevertheless, with the landmark Francovich case of November 19 1991, ${ }^{\text {XIX }}$ the European Court of Justice (ECJ) demonstrated that, under certain circumstances, citizens who have suffered damage as a result of a lack of implementation by a Member State can be entitled to compensation for this damage by the uncompliant Member State. This decision indubitably created a form of potential liability for those Member States that do not implement EU law, which goes far beyond the constitutionally permissible liability of American states in US. ${ }^{\mathrm{Xx}}$

And in cases of non-compliance, the Commission can make use of the 'EU-Pilot' scheme, which was designed to resolve compliance problems, through direct contact with Member States, without having to resort to infringement proceedings. ${ }^{\mathrm{xx}}$

Closely related to this issue is another highly relevant principle: the direct effect. The principle emerged from a decision of the ECJ, ${ }^{\mathrm{XXII}}$ and allows any citizen to invoke European law on his behalf, even if he is challenging the policies of his own Member State. 
While comparing different federal (or para-federal) systems, it is essential to highlight that the US constitutional system, being more than two centuries old, has more historically established procedures of articulation between the states and the centralised reality. On the other hand, it was only during the mid-1980s that the EU changed its procedures in order to facilitate the adoption of environmental directives and began substantial efforts to limit non-tariff barriers in the creation of a single market. Then, in the 1990s, an increased political influence of pro-environmental forces (mainly at the political level) emerged within the EU, with a number of green parties forming part of governments of western European nations and, at the same time, there was a decline in the influence of green pressure groups on American federal governments. During that period, a number of European environmental policies became more centralised - and more stringent compared to the reality of the US.

And, as a matter of fact, nowadays statistics have shown that more than 80 percent of environmental protection laws in force in EU Member States are now derived from decisions made in Brussels, home to the EU law-making bodies collectively referred to as the EU institutions (Martella and Francke 2012: 8). Consequently, it can be argued that having a classic constitutional federalism, such as in the US, does not mean that environmental law and policy is more harmonised in that federal state. And, at the same time, the political and 'constitutional' reality of the EU, often described as sui generis, has been changing into a more and more centralised reality in areas of environmental law and policy. Maybe this follows of the logic of Sadeleer (discussed above), who considers that the only way of eliminating environmental threats can be through coherent policies 'requiring joint efforts to achieve a high level of protection.'

However, according to Vogel, it is also true that

On one hand, the continued efforts of states in the US and member states of the EU to strengthen a broad range of environmental regulations suggest that fears of a regulatory race to the bottom may be misplaced. Clearly, concerns that strong regulations will make domestic producers vulnerable to competition from producers in political jurisdictions with less stringent standards have not prevented many states on both sides of the Atlantic from enacting many relatively stringent and ambitious environmental standards. On the other hand, the impact of such state policies remains limited, in part because not all states choose to adopt or vigorously enforce relatively stringent standards. Thus, in the 
long run, there is no substitute for centralised standards; they represent the most important mechanism of policy diffusion. (Vogel et al. 2010: 37-38)

And, in both the US and the EU, there are strong reasons to follow Arnold and Gunderson's perspective: that legal institutions need to help build adaptive capacity, not only among local or state (or even Member State in EU) communities and authorities, but also among federal environmental regulatory agencies and federal natural-resources management agencies (Arnold and Gunderson 2014: 324). This adaptive capacity means strong participatory and deliberative governance, adapting to extreme weather events, rising coastlines, or other environmental transformations, while also maintaining basic human freedom, dignity and rights. Only through this way is possible to guarantee a better and continuous articulation between Environmental law within the whole EU and also between its different Member States.

Other interesting examples of subsidiarity principle within a federal state could be presented with reference to the realities of Canada or Germany. In Canada, famous for having a large number of principles and norms not found in its formal constitutional structure (the 'unwritten constitution'), the principle 'aims to preserve local variation and diversity within a federation' (Kong 2015: 45). In Germany the Basic Law expressly provides in its article 72(2) - specifically dedicated to 'concurrent legislative powers' - that the Federation has the right to legislate on environmental matters, but only if and to the extent that the establishment of equivalent living conditions throughout the federal territory or the maintenance of legal or economic unity renders federal regulation necessary in the national interest.' Moreover, article 72(3) provides that, on matters of protection of nature and landscape management, 'if the Federation has made use of its power to legislate, the Länder may enact laws at variance with this legislation', which gives them a large margin to legislate, ensuring local variation and diversity as mentioned above, leaving more space for political than for legal or judicial discussion (Taylor 2006: 115-130).

However, in respect of the EU, it is true that, for a long time, the Union has been moving away from a model of regulation based on adopting legislation laying down binding legal obligations which intend to harmonise laws across all the territories of the Union. This political option has been an almost general trend, but it is particularly applicable for environmental protection law. Partly, this has been because of perceived inadequacies in 
old-style, 'command-and-control legislation' as it is, allegedly, neither flexible enough, nor responsive enough to the complex demands of environmental regulation (and which are to become ever more complicated and intricate as the EU is expanding - even more so with the particular episode of 'Brexit').

Nevertheless, the subsidiarity principle has also been presented as an answer to some of the problems that the EU has faced over its political and legal legitimacy. The reality is that there is still a perception that EU rulemaking is too remote from those it affects - its subjects - and does not sufficiently engage with the main stakeholders in different sectors and the wider public. And in a particular area such as environmental law, in which a wide array of private and public interests persists in the debate, that is a real problem. These were some of the arguments that ultimately dictated an important shift of focus towards what is nowadays known as EU environmental governance.

In fact, as Bell, McGillivray and Pedersen correctly state, there are three related features to this more recent development - which, it must be stressed, is already more and more concretely taking shape in the EU (Bell, McGillivray and Pedersen 2013: 206).

The first feature that should be mentioned is the move away from an exclusively 'topdown' approach to environmental law-making - from EU institutions to Member States to encompass decision-making processes that are more likely to involve both state and non-state actors. In the environmental field, an existing example could be highlighted and that is the 'Auto-Oil' initiative, which brought together different actors, such as the Commission, vehicle manufacturers and the oil industry in trying to tackle the environmental problem of air pollution, that could not be addressed coherently without, in effect, the problem being 'shared' by the two . XxIII

A second feature that could be mentioned is the consequence of taking the option of moving away from a focus on harmonisation - particularly concerning substantive harmonisation. This could be seen in the approach of the Court of Justice in the Standley case, in which the Member States were given an extensive degree of discretion in the issue of how to implement a Directive when it came to designating areas for protection. ${ }^{\text {xiv }}$

The third and final feature is that there is in practice an emphasis on using different regulatory techniques that seem to result in a better fit with this approach. Therefore, in place of binding standards set at an EU level, there is much greater emphasis on trying to stimulate improved environmental performance within the Member States and their 
stakeholders. This is through such strategies as learning and monitoring the market reality, as benchmarking and sharing best practice, but there is likely to be some legal force behind this approach. One example is the fact that legislation sets out, procedurally, the terms by which different information is generated, and requires that reports are published and reviewed by the Commission. The Directive 2009/28/EC, on the promotion of the use of energy from renewable sources, illustrates how this approach has already been taken.

In short, as a consequence there are multiple pressures to move away from the trend of legislative harmonisation (and even, as in the case of the environment, away from minimum harmonisation). The particular case of the 'Cardiff process', at the level of policy, could be seen as a far-reaching example of the approach we have discussed. ${ }^{\mathrm{XxV}}$ In time, it is possible that this new approach will also be extensively adopted instead of a reliance on traditional legal approaches such as the use of standard-setting Directives; these have always tended to predominate in environmental law, especially in those areas in which topics about subsidiarity are more strongly analysed and researched. But the evidence so far is that the option for 'new governance' approaches is used much less frequently than the usual rhetoric about them would suggest or even require (Holzinger, Knill and Schäfer 2006: 403).

There are evidently contrasting views on what is going on with European law in the environmental field. Some perspectives accept these developments as generally positive solutions, emphasising the need to grant Member States - and main actors - greater freedom to pursue environmental protection in ways that they consider to be the most appropriate, though against a backdrop of transparency, and structured evaluation and coordination. From another point of view, however, these developments can be seen in a more negative perspective, as substantive legal standards can, at least in principle, be enforced either through traditional legal means or, indirectly, by pressure groups raising awareness of non-compliance. Seen in this light, headlines reporting that Member States have breached EU law by failing to submit necessary evaluative reports on how they are combating pollution simply carry less force than similar publicity that Member States practising polluting behaviour (Bell, McGillivray and Pedersen 2013: 207).

These are only some examples of how EU environmental law has had a somewhat undecided status, hovering between centralisation and decentralisation, though tending most of the time towards a centralised approach. As already demonstrated, this option does 
not seem to be the optimum solution in the integration process. However, both Member States and the EU institutions have started to realise (even if slowly, in a limited way) that a more balanced approach - maybe through taking some characteristics of the US system as an example in environmental law - would potentially be a more reasonable pathway towards a green federalism for the EU.

At this point, it is also relevant to emphasise that the integration (or federalisation) of the $\mathrm{EU}$ is an ongoing process in which there is still a lot to adjust and evolve. In effect, one of the curious facts is that, while legislating in a myriad of environmental matters - in some cases with too much detail - EU environmental powers have been very shy in tackling economic and fiscal issues for the protection of environment and climate change adaptation, such as the case of carbon taxes, under the limits of the subsidiarity principle. And the truth is that current forecasts for EU institutional reforms and new developments on environmental policy are far of demonstrating this trend. Which means that the EU still needs to take bolder steps in these areas. However, environmental protection is, like the EU as a whole, also a process of adjustment and adaptation, especially in these times of climate uncertainty.

\section{Conclusions: the way ahead}

One of the most frequently offered criticisms of environmental decentralisation is, as previously demonstrated, the 'race to the bottom' thesis (Adelman 2014: 1-91), though the truth is that there is little empirical evidence to prove the theory with the application of the principle of subsidiarity. Differences in state policies may not necessarily lead to 'races to the bottom' or exacerbate rivalry, but rather result in positive spillover effects, such as drawing lessons from each other.

Decentralisation in environmental law and policy offers the possibility to create greater proximity to local concerns, improve representation, legitimacy, and efficiency. Nevertheless, as previously stated, some Member States which have more ambitious environmental agendas may enact certain green policies or measures without the spur of the EU, while at the same time other Member States would not do the equivalent and, at the end, the principles and the norms of the treaties would not be complied with by all Member States in the same way. 
In reality, nowadays there is a myriad of environmental issues that cannot remain local: regional and global problems and the effects of environmental mismanagement cross state and national borders, notably where the impacts of climate change are concerned, in a world that each day evolves more and more rapidly. From problems such as transboundary pollution or conservation of endangered species to the extremely challenging needs of more effective solutions such as knowledge and research on environmental management, most of the time it is necessary to expand approaches to gain the economies of scale to solve larger environmental problems (Chakrabarti and Srivastava 2015: 2-3). And that is the primary argument for an expanded approach of solving environmental problems in the territory of the EU, but also in the rest of the world.

Environmental federalism requires comprehensive research on the appropriate jurisdictions for the management and provision of environmental goods and services, depending on territorial, historical and cultural realities. For example, it makes sense that from the US's perspective, harmonisation is not so necessary than in the case of EU, where after only 60 years of integration it is obvious that historically different national and traditional characteristics still exist and will continue to persist in the future, even with a strong will for integration. In this case, and in order to meet similar developmental indicators, harmonisation is absolutely necessary, both from the legal and policy perspectives.

Following the analysis from Martella and Francke:

\footnotetext{
The extent to which federalism will extend to implementation and enforcement of EU environmental protection laws remains to be seen. Companies that operate across the EU might like to see more harmonized implementation and enforcement of EU environmental protection laws. Yet there remains a need for meaningful changes to the administrative rulemaking process, starting ideally with publically transparent and legally binding administrative standards, both procedural (e.g., in terms of standing) and substantive (e.g., in terms of cross-boundary uniformity). Until this happens, private companies doing business in the EU will continue to look to individual Member States' implementation and enforcement of EU environmental protection laws to offset the Commission's largely unchecked rulemaking powers (Martella and Francke 2012: 6).
}

Consequently, when taking action under the principle of subsidiarity, the EU is obliged to state reasons pursuant to the TEU and Protocol No 2, including those which reveal that 
the political institutions consider that the action is consistent with the principles of subsidiarity and proportionality. Therefore, to maintain a balance between better management of local realities and, at the same time, a global control of compliance to the principles of the treaties, it is essential for all EU institutions (including the necessary interpretations from the ECJ) and Member States, to follow a process of integration that must be aware of this need of articulation between all those principles and, at the same time, the specificities of different territories and communities.

Following van Zeben (2014), it is noteworthy to emphasise that non-transparent and non-judiciable European decision-making processes, on the allocation of power between the EU institutions and the Member States, may possibly lead to an undermining of the legitimacy of both the EU's and Member States' regulatory power and action. And this way might create a reduced feeling of confidence among the different actors and stakeholders (institutions, multinational companies, pressure groups, associations and, especially, citizens). For that reason, van Zeben proposes the option of substantiating the principle of subsidiarity in meaningful ways, for instance through a competence allocation approach, as a way to start to strengthen the principle in a more practical and positive way (van Zeben 2014: 464).

Clearly, the critical view of subsidiarity within the EU should not be mistaken for a more general preference for decentralisation within the territory of the Member States. There are many governance and policy areas that have benefitted from the option of centralisation, particularly in environmental fields, or that would not have existed without coordination by EU institutions and their specialised agencies. Nevertheless, it would be extremely naive to believe that political options for centralisation should continue to exist in the EU without a strong and extensive legal basis, as well as with more room for judicial review.

Over the last decades, EU leaders and legislators have been working in, and researching into, a unique and sui generis species of a federal system, while striving to face and overcome economic and political crises. And during these difficult periods, the temptation to adopt an ad hoc approach to power sharing between the EU institutions and the Member States has gained strength, and has often seemed to favour more and more centralisation, notwithstanding Member States'strong protests. 
As a matter of fact, the recent case of 'Brexit' is an example of how the political perspectives and even protests of Member States - and especially of their citizens - are often disregarded by EU institutions and their leaders. This is one of the reasons why the process of building a federal EU must take into account the citizens that support the Union and who, ultimately, vote and elect those who are to act as public officials, responsible for the future political and legal choices, both of the EU and the Member States. Here, the mechanisms of public participation and other new adaptive (or even 'smarter') instruments for law- and decision-making - such as decentralised and iterative processes discussed above - assume an extremely relevant role (Cosens et al. 2017: 30). This is particularly relevant in environmental issues, always which concern concrete, but changeable and evolving realities that are intrinsically connected to the idiosyncrasies and specific characteristics of each territory and each community living there. As a consequence, it is reasonable to conclude that a future EU green federalism has to be based on both centralised and decentralised elements and processes.

The perspective presented in this article means that it is only through the abovementioned balancing process that it might be possible for all actors (from public to private sectors, different Member States, multinational companies, pressure groups and citizens) to work together to ensure a distributed governance of the environment across the existent multiple levels of jurisdiction, for regulation, implementation, and monitoring by reference to their respective capabilities (Lenaerts 1993: 893-895).

\footnotetext{
* The author is a doctoral researcher in public law at Lisbon Nova Law School, Universidade Nova de Lisboa, with a doctoral scholarship from the Portuguese Foundation for Science and Technology, and Fulbright Visiting Student at Louis D. Brandeis School of Law, University of Louisville. Member of CEDIS Research Centre for Law and Society, at Lisbon Nova Law School, the Environmental Regulatory Research Group, at the School of Law of the University of Surrey, and the Center for Land Use and Environmental Responsibility, at the School of Urban and Public Affairs of the University of Louisville. Special thanks to Dr. Ana Rita Gil and Dr. Samo Bardutzky for their helpful comments when this paper was discussed in the conference The Federal Experience of the European Union: Past, Present and Future, on May 22, 2017, at Lisbon Nova Law School. Please direct any comments or questions to tiagocartaxo@,fd.unl.pt.

I Article 130r(4) EEC: 'The Community shall take action relating to the Environment to the extent to which the objectives referred to in paragraph 1 [to preserve, protect and improve the quality of the environment; to contribute towards protecting human health; and to ensure prudent and rational utilization of natural resources] can be attained better at Community level than at the level of the individual Member States. Without prejudice to certain measures of Community nature the Member States shall finance and implement the other measures.'

II Article 3b EC: 'The Community shall act within the limits of the powers conferred upon it by this Treaty and of the objectives assigned to it therein.

In areas which do not fall within its exclusive competence, the Community shall take action, in accordance with the principle of subsidiarity, only if and in so far as the objectives of the proposed action cannot be
} 
sufficiently achieved by the Member States and can therefore, by reason of the scale or effects of the proposed action, be better achieved by the Community.

Any action by the Community shall not go beyond what is necessary to achieve the objectives of this Treaty.' III Article B, last paragraph, TEU (1992): 'The objectives of the Union shall be achieved as provided in this Treaty and in accordance with the conditions and the timetable set out therein while respecting the principle of subsidiarity as defined in Article 3b of the Treaty establishing the European Community.'

IV Commission Report to the European Council on the Adaptation of Community Legislation to the Subsidiarity Principle, COM (93) 545 (November 1993).

$\mathrm{V}$ The protocol, which was also adopted in 1997, established the conditions for the application of the principles of subsidiarity and proportionality enshrined in Article $3 \mathrm{~b}$ of the EC Treaty "with a view to defining more precisely the criteria for applying them and to ensure their strict observance and consistent implementation by all institutions.'

VI Article 5(3) TEU: 'Under the principle of subsidiarity, in areas which do not fall within its exclusive competence, the Union shall act only if and in so far as the objectives of the proposed action cannot be sufficiently achieved by the Member States, either at central level or at regional and local level, but can rather, by reason of the scale or effects of the proposed action, be better achieved at Union level.

The institutions of the Union shall apply the principle of subsidiarity as laid down in the Protocol on the application of the principles of subsidiarity and proportionality. National Parliaments ensure compliance with the principle of subsidiarity in accordance with the procedure set out in that Protocol.'

VII The protocol referred to establishes the conditions for the application of the principles of subsidiarity and proportionality and a system for monitoring the application of those principles, as well as sets that the protocol shall be annexed to the Treaty on European Union and to the Treaty on the Functioning of the European Union.

VIII Previous article A, second paragraph.

IX Article 2, Protocol No 2 .

$\mathrm{x}$ Article 5, Protocol No 2.

XI Some authors consider that far too much authority has been allocated to the European level and, in some cases, more than would be necessary to avoid transboundary externalities. In this sense, see Van den Bergh, Faure and Lefevere (1996).

XII Article 6, Protocol No 2

XIII Article 5(4) TEU: '[u]nder the principle of proportionality, the content and form of Union action shall not exceed what is necessary to achieve the objectives of the Treaties.'

XIV As examples of these kind of more open legal solutions are Directive 2000/60/EC of the European Parliament and of the Council of 23 October 2000, establishing a framework for Community action in the field of water policy, or Directive 2008/56/EC of the European Parliament and of the Council of 17 June 2008 establishing a framework for community action in the field of marine environmental policy.

$\mathrm{XV}$ In the words of Krämer, 'The European Union (EU) does not enjoy the prerogatives of a state; it may act only where it has been expressly so authorised by the Treaty. Any comparison with domestic environmental law in the Member States, or with that of the USA is therefore necessarily misleading' (Krämer 2004: 155).

XVI As an example of that time, President Richard Nixon asked Congress, in 1970, to pass more stringent standards based on the lowest pollution levels attainable using developing technology. Congress responded by enacting the technology-forcing Clean Air Act Amendments of 1970, which required automakers to reduce their emissions of carbon monoxide and hydrocarbons by 90 per cent within five years and their emissions of nitrogen oxides by 90 per cent within six years. These drastic reductions were intended to close the large gap between ambient urban air pollution concentrations and the federal health-based Nationally Uniform Ambient Air Quality Standards established pursuant to the US Clean Air Act. Curiously, California was permitted to retain and/or enact more stringent standards, though these were specified in federal law (Vogel et al. 2010: 7).

XVII Article 5(1) TEU: 'The limits of Union competences are governed by the principle of conferral. The use of Union competences is governed by the principles of subsidiarity and proportionality.'

XVIII Article 5(2) TEU: 'Under the principle of conferral, the Union shall act only within the limits of the competences conferred upon it by the Member States in the 'Treaties to attain the objectives set out therein. Competences not conferred upon the Union in the Treaties remain with the Member States.'

XIx See Judgment of the Court of 19 November 1991, Andrea Francovich and Danila Bonifaci and others $v$ Italian Republic (joined cases C-6/90 and C-9/90). 
xx On this issue, see the example of Seminole Tribe of Florida v. Florida, 517 U.S. 44 (1996), in which the U.S. Supreme Court held that Congress cannot alter the states' immunity from suit by private citizens that is granted by the Eleventh Amendment of the U.S. Constitution, unless it makes its intention to do so 'unmistakeably clear' in the language of the statute.

XxI The 'EU-pilot' scheme was launched by the Commission in April 2008 to test a new problem-solving mechanism involving 15 Member States: Austria, the Czech Republic, Denmark, Germany, Finland, Hungary, Ireland, Italy, Lithuania, the Netherlands, Portugal, Slovenia, Sweden, Spain and the United Kingdom. This allows the Commission to refer correspondence and complaints directly to the Member State for comment and resolution. The Commission is kept informed and has the option of taking further action, also through the launching of infringement procedures, where necessary.

xxII See Judgment of the Court of 5 February 1963, NV Algemene Transport- en Expeditie Onderneming van Gend \& Loos v Netherlands Inland Revenue Administration (Case 26-62). According to the ECJ, the question whether individual rights could be found directly in Community law was dependent solely upon the contents and wording of the European legislation concerned, with national legislation playing no role in this issue.

XXIII It is notable that this initiative resulted in traditional regulatory standards being adopted and that it has, in fact, been criticised by some authors, mainly because: i) it took some four years to negotiate an agreement that would bite some ten years after it was concluded. The new solution was hardly a swift alternative to the legislative process that would be expected to finalise a Directive, which could be transposed and implemented easily within that timetable; ii) there was little wider public participation in the negotiation of the agreement, which was largely conducted between the Commission and the associations involved. In addition to these arguments, compliance data would only be made public on a collective basis across the whole sector, meaning that individual manufacturer's performance would not be evaluated; iii) there were no enforcement mechanisms for non-compliance cases; iv) the defined targets had become outdated by the foreseeable introduction of existing technologies. As a matter of fact, the targets represented a 'business as usual' model that would not necessarily stabilise $\mathrm{CO}_{2}$ emissions discharged from passenger cars at 1999 levels by 2010; and v) the targets did not act as sufficient incentives in order to develop alternative technologies to the already existing ones (Volpi and Singer 2000; Bell, McGillivray and Pedersen 2013: 575).

xxIv The mentioned Case C-293/97 - The Queen v Secretary of State for the Environment and Ministry of Agriculture, Fisheries and Food, ex parte H.A. Standley and Others and D.G.D. Metson and Others involved a challenge that the Government of the United Kingdom, when drawing up its initial list of nitrate vulnerable zones (NVZs) under the Agricultural Nitrates Directive (91/676/EEC), had failed to consider whether the excessive nitrate levels were caused by non-agricultural sources. The farmers argued that the mentioned failure discriminated against agricultural users in the NVZ, because the cost of reducing the nitrate concentrations to an acceptable level was to be borne wholly by the farmers when there were other users that may have been responsible for the nitrate pollution. The case was referred to the Court of Justice and the Court upheld the approach of the Government in identifying waters in which agricultural sources made a 'sufficient contribution' to excessive nitrate levels, in line with a purposive interpretation of the respective Directive. Indeed, the Court hinted that something rather less than a significant contribution might have been enough, showing the amount of freedom that Member States are to enjoy. The referred flexibility is also demonstrated in the Court's rejection of an argument that the UK violated the Polluter Pays Principle (now foreseen in Article 192(2) TFEU), because the Directive had a sufficient margin to ensure that action programmes targeted the contribution of farmers proportionate to those of other polluter stakeholders.

xxv The 'Cardiff Process' is the name given to the process launched by European heads of state and government (The European Council) at their meeting in Cardiff, in June 1998, requiring different Council formations to integrate environmental considerations into their respective activities, putting article 6 of the EC Treaty into practice. The Cardiff process has contributed to raising the political profile of integration, the latter now being regularly discussed at the highest political level. The Cardiff process has also generated a sense of ownership of environmental integration in some Council formations with positive knock-on effects on actions in other EU institutions and Member States. 


\section{References}

- $\quad$ Adelman David E., 2014, 'Environmental Federalism When Numbers Matter More than Size', UCLA Journal of Environmental Law \& Policy, XXXII(2).

- Arnold Craig Anthony (Tony) and Gunderson Lance H., 2014, 'Adaptive Law', in Garmestani Ahjond S. and Allen Craig R. (eds), Social-Ecological Resilience and Law, Columbia University Press, New York, 317-364.

- Arribas Gracia Vara and Bourdin Delphine, 2012, 'What Does the Lisbon Treaty Change Regarding Subsidiarity within the EU Institutional Framework?', Eipascope, Bulletin No 2012/02, European Institute of Public Administration. Available at: http://www.eipa.eu/files/repository/eipascope/20130117091515 Eipascope2012 2web.pdf (retrieved on October 7, 2018).

- Barnard Catherine and Peers Steve, 2014, European Union Law, Oxford University Press, Oxford.

- Bell Stuart, McGillivray Donald and Pedersen Ole W., 2013, Environmental Law, 8 ${ }^{\text {th }}$ ed., Oxford University Press, Oxford.

- Van den Bergh Roger, Faure Michael and Lefevere Jurgen, 1996, 'The Subsidiarity Principle in European Environmental Law: An Economic Analysis', in Eide Ehrling and Van den Bergh Roger (eds), Law and Economics of the Environment, Juridisk Forlag, Oslo, 121-166.

- Chakrabarti P.G. Dhar and Srivastava Nidhi, 2015, Green Federalism: Experiences and Practices, The Energy and Resources Institute and Forum of Federations, Ottawa.

- Cosens A. Cosens, Craig Robin K., Hirsch Shana Lee, Arnold Craig Anthony (Tony), Benson Melinda H., DeCaro Daniel A., Garmestani Ahjond S., Gosnell Hannah, Ruhl J.B. and Schlager Edella, 2017, 'The role of law in adaptive governance', Ecology and Society, XXII(1): 1-30.

- Faure Michael G. and Johnston Jason Scott, 2009, 'The Law and Economics of Environmental Federalism: Europe and the United States Compared', Virginia Environmental Law Journal, XXVII(3): 205-274.

- Gottlieb Robert, 1993, Forcing the Spring: The Transformation of the American Environmental Movement, Island Press, Washington D.C..

- Holzinger Katharina, Knill Christoph and Schäfer Ansgar, 2006, 'Rhetoric or Reality? "New Governance" in EU Environmental Policy', European Law Journal, XII(3): 403-420.

- Jans Jan and Vedder Hans, 2012, European Environmental Law: After Lisbon, Europa Law Publishing, Groningen.

- $\quad$ Kohler-Koch Beate and Eising Rainer (eds), 1999, The Transformation of Governance in the European Union, Routledge, London and New York.

- $\quad$ Kong Hoi L., 2015, 'Subsidiarity, Republicanism, and the Division of Powers in Canada', Revue de droit de l'Université de Sherbrooke (RDUS), XLV: 13-46.

- Krämer Ludwig, 2002, 'Thirty Years of EC Environmental Law: Perspectives and Perspectives', The Yearbook of European Environmental Law, II: 155-182.

- Krämer Ludwig, 2004, 'The Routes of Divergence: A European Perspective', in Vig Norman J. and Faure Michael G. (eds), Green Giants? Environmental Policies of the United States and the European Union, MIT Press, Cambridge MA and London.

- $\quad$ Krämer Ludwig, 2012, EU Environmental Law, Sweet \& Maxwell, London.

- Langlet David and Mahmoudi Said, 2016, EU Environmental Law and Policy, Oxford University Press, Oxford.

- Lenaerts Koen, 1993, 'The Principle of Subsidiarity and the Environment in the European Union: Keeping the Balance of Federalism', Fordham International Law Journal, XVII(4): 846-895.

- Martella Roger and Francke Glory, 2012, 'Federalism in European Environmental Decision Making', Natural Resources \& Environment, XXVII(1): 1-6.

- $\quad$ Sadeleer Nicolas de, 2012, 'Particularités de la subsidiarité dans le domaine de l'environnement', Droit et Société, no. 80: 73-90.

- Taylor Greg, 2006, 'Germany: The subsidiarity principle', International Journal of Constitutional Law, IV(1): 115-130.

- Vogel David, Toffel Michael, Post Diahanna and Aragon Nazli Z. Uludere, 2010, 'Environmental Federalism in the European Union and the United States', Working Paper 10-085, Harvard Business School. Available at: http://www.hbs.edu/faculty/Publication\%20Files/10-085.pdf (retrieved on October 7, 2018). 
- $\quad$ Volpi Giulio and Singer Stephan, 2000, Will Voluntary Agreements at EU Level Deliver on Environmental Objectives? Lessons from the Agreement with the Automotive Industry, WWF Discussion Paper.

- $\quad$ van Zeben, Josephine, 2014, 'Subsidiarity in European Environmental Law: A Competence Allocation

Approach', Harvard Environmental Law Review, XXXVIII(2): 415-464. Available at SSRN: https://ssrn.com/abstract $=2791617$ (retrieved on October 7, 2018). 